\title{
New Casemix Classification as an Alternative Method for Budget Allocation in Thai Oral Healthcare Service: A Pilot Study
}

\section{Thunthita Wisaijohn, ${ }^{1}$ Atiphan Pimkhaokham, ${ }^{2}$ Phenkhae Lapying, ${ }^{3}$ Chumpot Itthichaisri, ${ }^{2}$ Supasit Pannarunothai, ${ }^{4}$ Isao Igarashi, ${ }^{1}$ and Koichi Kawabuchi ${ }^{1}$}

\author{
${ }^{1}$ Healthcare Economics, Graduate School of Medical and Dental Sciences, Tokyo Medical and Dental University, \\ Tokyo 113-8510, Japan \\ ${ }^{2}$ Department of Oral and Maxillofacial Surgery, Faculty of Dentistry, Chulalongkorn University, Bangkok 10330, Thailand \\ ${ }^{3}$ Dental Health Bureau, Department of Health, Ministry of Public Health, Nonthaburi 11000, Thailand \\ ${ }^{4}$ Faculty of Medicine, Naresuan University, Phitsanulok 65000, Thailand
}

Correspondence should be addressed to Atiphan Pimkhaokham, atiphan.p@chula.ac.th

Received 27 April 2010; Revised 29 June 2010; Accepted 15 July 2010

Academic Editor: Stephen Richmond

Copyright () 2010 Thunthita Wisaijohn et al. This is an open access article distributed under the Creative Commons Attribution License, which permits unrestricted use, distribution, and reproduction in any medium, provided the original work is properly cited.

\begin{abstract}
This study aimed to develop a new casemix classification system as an alternative method for the budget allocation of oral healthcare service (OHCS). Initially, the International Statistical of Diseases and Related Health Problem, 10th revision, Thai Modification (ICD-10-TM) related to OHCS was used for developing the software "Grouper". This model was designed to allow the translation of dental procedures into eight-digit codes. Multiple regression analysis was used to analyze the relationship between the factors used for developing the model and the resource consumption. Furthermore, the coefficient of variance, reduction in variance, and relative weight (RW) were applied to test the validity. The results demonstrated that 1,624 OHCS classifications, according to the diagnoses and the procedures performed, showed high homogeneity within groups and heterogeneity between groups. Moreover, the RW of the OHCS could be used to predict and control the production costs. In conclusion, this new OHCS casemix classification has a potential use in a global decision making.
\end{abstract}

\section{Introduction}

There are many insurance systems worldwide for Universal Healthcare Coverage. In Thailand, health insurance systems are categorized into three major schemes: the Civil Servant Medical Benefit Scheme (CSMBS), the Social Security Scheme (SSS), and the Universal Coverage Scheme (UCS) or the "30 baht (in 2002, 43.0 Baht/US\$ copayment) for all diseases" (UCS was implemented in May 2001 and introduced nationwide in April 2002) [1]. In 2006, the UCS abolished the 30 baht copayment per visit and made the UCS free [2]. In the past, the health budget was allocated by the characteristics of each healthcare provider, the number of doctors, and the number of patient beds. Thus, healthcare resources were not equitably allocated between the health insurance systems [3]. In 2001, the revamping of the health insurance system was initiated to restructure the methodology and the system allocating healthcare resources by the Health Systems Research Institute $[4,5]$. One key difference between the insurance schemes is that the UCS separated the provider budget between the inpatient and the outpatient for exclusive capitation. Under this paradigm, the outpatient budget was allocated on the basis of the capitation rate, while the inpatient budget was allocated on the basis of Diagnosis Related Group (DRG) within a global budget [1].

Under the UCS, the budget for the oral healthcare service (OHCS), based on the benefit package, is part of the outpatient and Promotion/Prevention budget, to share financial risks among OHCS and general health services. While the budgets for all capital investment budgets are allocated by the Ministry of Public Health (MOPH) regional 
regulators' judgment, the OHCS, unfortunately, is usually the last priority. Therefore, the efficiency of the allocation is doubted, mainly the methodology and reliability aspect, as follows: (1) Since the Universal Healthcare Coverage policy was established in the year 2001, the demands for government-funded OHCS have increased significantly. In particular, the demand for dental substitution, which is highly expensive, has increased [6]. The per capita budget for all healthcare service in the fiscal year of 2003 was the same amount as the previous year, approximately 1,202 baht ( 43.0 Baht/US\$) [7, 8] and became 2,202 Baht (34.34 Baht/US\$) in 2009. (2) Current budget allocation has not been categorized for OHCS separately, and there have been few cost studies of OHCS. The information on the cost of these service activities is scarce, leading to a shortage of information for making management decisions. Thus, cost studies of OHCS are important and necessary for the evaluation of healthcare managerial efficiency and resource allocation, as well as for generating the appropriate parameters to use in making policies for healthcare service improvement in the context of budgetary constraints $[9,10]$.

Casemix is a generic term for the patients' classification system, including inpatient and outpatient status, budgeting allocation, and payment [11]. Successful outcomes from the adoption of a casemix system have been shown in many countries [12-14]. The best-known classification system used in a casemix funding model is the DRG. The DRG classifies acute inpatient episodes into a discrete number of manageable categories, depending on their clinical condition and resource consumption, assigned by a grouper program based on their demographics, clinical information (diagnosis (Dx) and procedure (Proc) codes), and comorbidity. The DRG method has been well evaluated for classifying inpatient treatment $[15,16]$. In Thailand, the initial DRG was implemented in 1999 and several successive versions have been developed. Pannarunothai's studies on DRG development in Thailand recommended that casemix systems should be used in the budget allocation for the healthcare service system $[11,17]$.

In Thailand, most people are covered by the aforementioned insurance schemes, although the budget allocations and payment systems are different between the schemes. DRG is currently employed as an allocation method only for inpatient healthcare budgets and not for all healthcare budgets. However, the DRG system has limitations in reflecting the OHCS cost. The future development of the appropriate inpatient and outpatient casemix for OHCS is important and necessary for economic healthcare management [17].

For the above-described reasons, the development of a new casemix classification in OHCS is desirable. This study aimed to develop and examine the feasibility of a new casemix classification system as an alternative method for budget allocation in Thai OHCS. These three schemes were each adapted, on the basis of DRG, as an alternative method to inpatient and outpatient-related OHCS for budget allocation $[11,18,19]$. This system might, in time, be applied in other countries healthcare system for OHCS resource allocation as well.

\section{Materials and Methods}

This study was conducted utilizing the electronic data of individual patients treated from April 2008 to March 2009 at three selected tertiary hospitals that met the study's inclusion criteria. The study protocol was approved by the Ethics Committee of the participating hospitals. The inclusion criteria were the use of the International Classification of Diseases, 10th edition (ICD-10) and International Classification of Disease, 9th edition, Clinical Modification (ICD9-CM) for the clinical records $[20,21]$ and the systematic keeping of a database record that was based on a global coding of the clinical records. These databases contained information on inpatient and outpatient care utilization, including demographic data (date of birth (DOB), age, and gender), clinical information (Dx, Proc), and resource consumption (hospital charge, admission date, discharge date and type, length of stay (LOS), and health insurance). The five main methods used to develop a new casemix classification as an alternative method for budget allocation of OHCS in this study were coding, classification, costing, calibration, and payment.

\subsection{Coding. The coding process was divided into two parts.}

Part I. The development of the new casemix classification for OHCS began with the adoption of the ICD-10, ICD-9-CM, Current Dental Terminology 2007 (CDT) [22], International Statistical of Diseases and Related Health Problem, 10th revision, Thai Modification (ICD-10-TM) [23, 24], Thai DRG version 4 [25], and International Refined DRG (IRDRG) [26]. The study designed the analysis method in two steps. Step one, the ICD-10-TM for Dx and Proc codes related to OHCS were retrieved by a researcher and approved by five dentists with more than ten years of clinical experience and specialists in OHCS. Step two, these codes were then mapped to ICD-10 for Dx and ICD-9-CM for Proc by Program Map version 1.0, copyright of Thai health coding center, Cluster for Health Information Division, Bureau of Policy and Strategy, MOPH, Thailand. These selected codes were used as inclusion lists of principal diagnoses (PDx) and procedures (Proc).

Part II. The electronic data of individual patients from the three selected tertiary hospitals were checked based on the inclusion lists of PDx and Proc (Figure 1).

2.2. Classification. To develop a new casemix classification system for Thai OHCS, a specially designed computer software program called "Grouper" was used. Grouper was able to allocate each episode to a DRG according to the clinical information and other relevant data. This program used clinical and demographic data as the input and produced a corresponding DRG as the output [27].

The OHCS casemix classification model (Grouper) consisted of one procedure in one visit that classified cases into two main groups: the oral and maxillofacial surgery (OMFS) group, designated $\mathrm{M}$, and the tooth and periodontium 


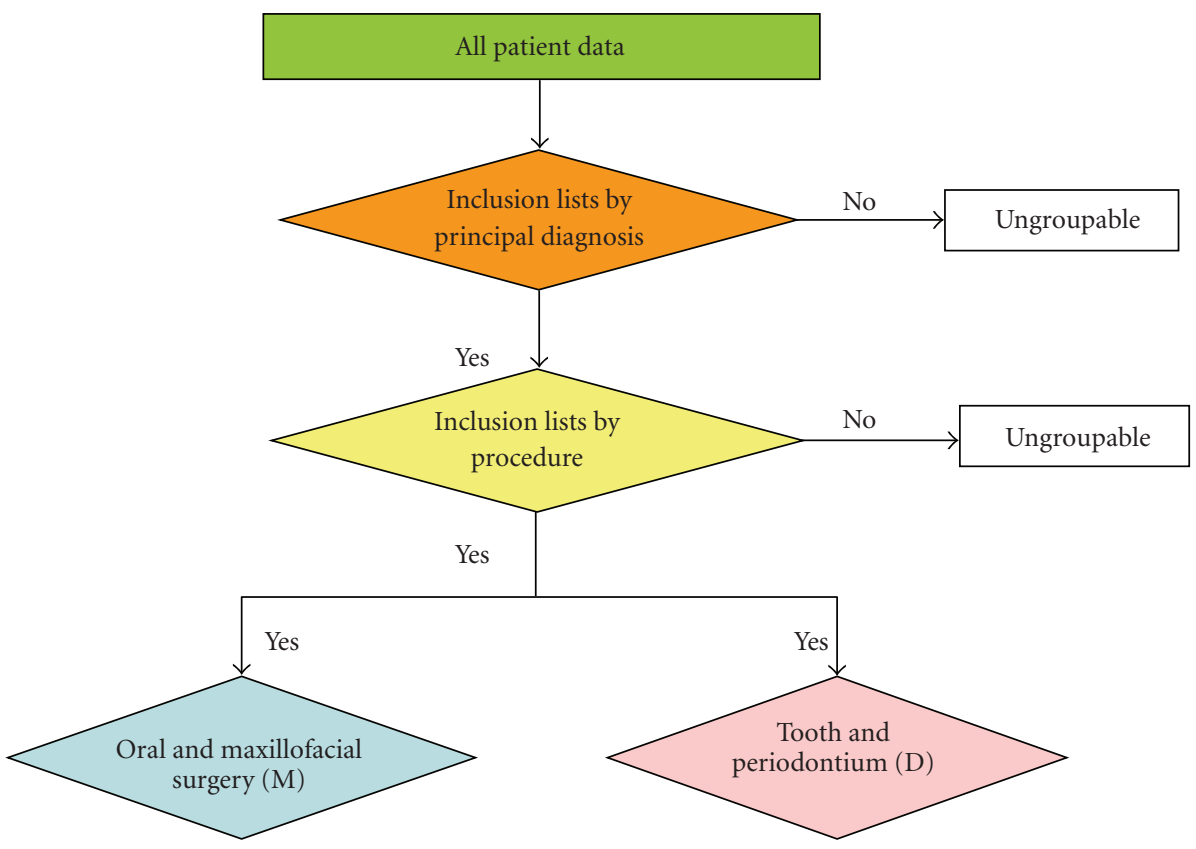

FIGURE 1: Diagram presents the steps one and two.

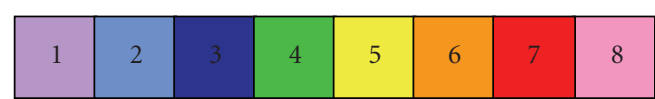

1 Represents the two main groups of oral and maxillofacial surgery, designated $\mathrm{M}$, or tooth and periodontium, designated D.

$2 \quad 3$ Represents the procedure clusters using anatomy group by body region as shown in ICD-10-TM.

5 Represents the subgroups of procedure clusters by root operation as shown in ICD-10-TM.

6 Represents the level of the complexity; 1 (one) for a simple procedure, 2 (two) for a complex procedure, and 3 (three) for a multidisciplinary or complex procedures.

Represents the general anesthesia (GA); 1 (one) represented GA and 0 (zero) was non-GA.

8 Represents the complication and comorbidity (CC); 1 (one) was CC and 0 (zero) was non-CC.

For examples: M0802311 (maxilla, operative procedures, level 3, with GA and with CC)

D0527200 (tooth restoration, resin-based composite restorations, level 2, without GA and without CC)

FIGURE 2: Diagram presents the casemix classification model of OHCS (one procedure in one visit) as represented in eight-digit codes.

group, designated D. Multiple procedures in one visit were designated as $\mathrm{P}$. The variables used for the OHCS grouping were included (1) PDx, (2) secondary diagnosis (SDx), (3) Proc (which were classified by the level of complexity by the same expert group), (4) anatomy group by body regions related to ICD-10-TM (Table 1), (5) root operation related to ICD-10-TM (Table 2), (6) general anesthesia (GA), and (7) complication and comorbidity (CC), using the Charlson index. This classification system was developed to allow the translation of dental procedures into eight-digit codes as summarized in Figures 2, 3, 4, and 5.
2.3. Costs. Initially, multiple regression analysis was used to study the relationship between the factors used for developing the codes and resource consumption. This analysis was employed to explore the relationship between the cost of $\mathrm{P}, \mathrm{D}$, and $\mathrm{M}$ (dependent variables) and several independent variables including, GA, CC, number of procedures in one visit, Proc (separated by the level of complexity), and LOS. Cross-validation was used to test the validation of the casemix in a separate set of data. Crossvalidation showed the quality of the prediction equation between the structure data and the data for validation. 
TABLE 1: Examples of both groups ( $M$ and D), split into procedure clusters using the anatomy group by body region.

\begin{tabular}{lc}
\hline OMFS groups (anatomical body region) & Code M \\
\hline Scalp & M01 \\
Include: scalp and subgaleal soft tissues & M02 \\
Skull & M03 \\
Cranial nerves X, Trigeminal nerve & M04 \\
Cranial nerves X1, Accessory nerve & M05 \\
Cranial nerve XII, Hypoglossal nerve & M06 \\
Cranial nerves & M07 \\
Face & M08 \\
Maxilla & M09 \\
Mandible & Code D \\
\hline Tooth and periodontium group & \\
(anatomical body region) & D01 \\
Oral examination & D02 \\
Radiographs/Diagnostic imaging & D03 \\
Preventive dentistry & D04 \\
Oral hygiene instructions and counseling & D05 \\
Tooth restoration & D06 \\
Endodontic treatment &
\end{tabular}

M: oral and maxillofacial surgery (OMFS) corrects a wide spectrum of diseases, injuries, and defects in the head, neck, face, jaws, and the hard and soft tissues of the oral and maxillofacial region.

D: tooth and periodontium: periodontium refers to the specialized tissues that surround and support the teeth (small, calcified, whitish structures found in the jaws (or mouth)) maintaining them in the maxilla and mandible.

TABLE 2: Examples of the procedure clusters, split into subgroups of procedure clusters using a root operation.

\begin{tabular}{lc}
\hline OMFS groups (root operation) & Code M \\
\hline Scalp & \\
Include: scalp and subgaleal soft tissues & M01 \\
Diagnostic procedures and non-operative & M0101 \\
procedures & M0102 \\
Operative procedures & M0104 \\
Miscellaneous procedures & M0199 \\
Other procedures and operations & Code D \\
\hline Tooth and periodontium (root operation) & D01 \\
\hline Oral examination & D0121 \\
Oral examination procedures & D02 \\
Radiographs/Diagnostic imaging & D0222 \\
Intraoral film & D0223 \\
Extraoral film & D0299 \\
Others &
\end{tabular}

M: oral and maxillofacial surgery (OMFS).

D: tooth and periodontium.

The higher confidence obtained from the cross-validation, the more suitable the estimation of the population prediction equation.
2.4. Calibration. Three statistical analyses, the coefficient of variation $(\mathrm{CV})$, the reduction in variance (RIV), and the relative weight (RW), were applied to verify the minimum variation within each group, the maximum variation among groups, and the assignment of a payment weight for the new casemix classification, respectively.

The CV is calculated as the standard deviation divided by the arithmetic mean. The $\mathrm{CV}$ value demonstrates the homogeneity of the cases within each group. A high $\mathrm{CV}$ indicates wide variation within each group. The accepted standard for $\mathrm{CV}$ is that each class should have a CV of less than 1.0 [15]. The expected end results using the new grouper program are groups of cases that are clinically similar and/or homogeneous with respect to resource use.

The RIV statistic is commonly used to assess the overall performance of the grouping method by comparing the variances of cost before and after grouping. The RIV was also related to the amount of variation within the data that requires explanation. A higher RIV reflected better performance of the grouping.

The RW is a measure of the resources used: it compares the average resource used in each group with the average resource used in all cases. In this study, statistical outliers beyond three standard deviations of the average cost for each OHCS classification were eliminated [28-30]. The RW was computed based on the cost data. It was defined in our study as the mean cost in each group divided by the mean costs of all patients. The cost in this study focused only on the cost of surgery, including general and local anesthesia, medical devices and instruments, and medical supplies. The staff cost was not included in this study because it was not paid on a per case basis. In Thailand, all staff salary is paid by the government and is dependent on the degree of education and the years of experience. Furthermore, the standard of staff cost has not been well established in Thailand.

2.5. Payment. A payment calculation was necessary to establish the prospective payment system. The payment was calculated using the RW of the OHCS classification multiplied by the current reimbursement rate (average base rate) in each group.

\section{Results}

\subsection{Coding}

Part I (Steps One and Two). The ICD-10-TM, consisting of 813 diagnoses and 1,090 procedures related to OHCS, were retrieved and mapped to ICD-10 and ICD-9-CM, respectively.

Part II. The electronic data of individual patients from three selected tertiary hospitals were checked by an inclusion list of PDx and Proc. There were 16,165 (84.64\%) cases out of 19,098 initial cases (cases with incomplete data were eliminated) that met the inclusion criteria. The number of inpatient and outpatient cases were 2,709 (16.8\%) and $13,456(83.2 \%)$, respectively. The demographic details, 


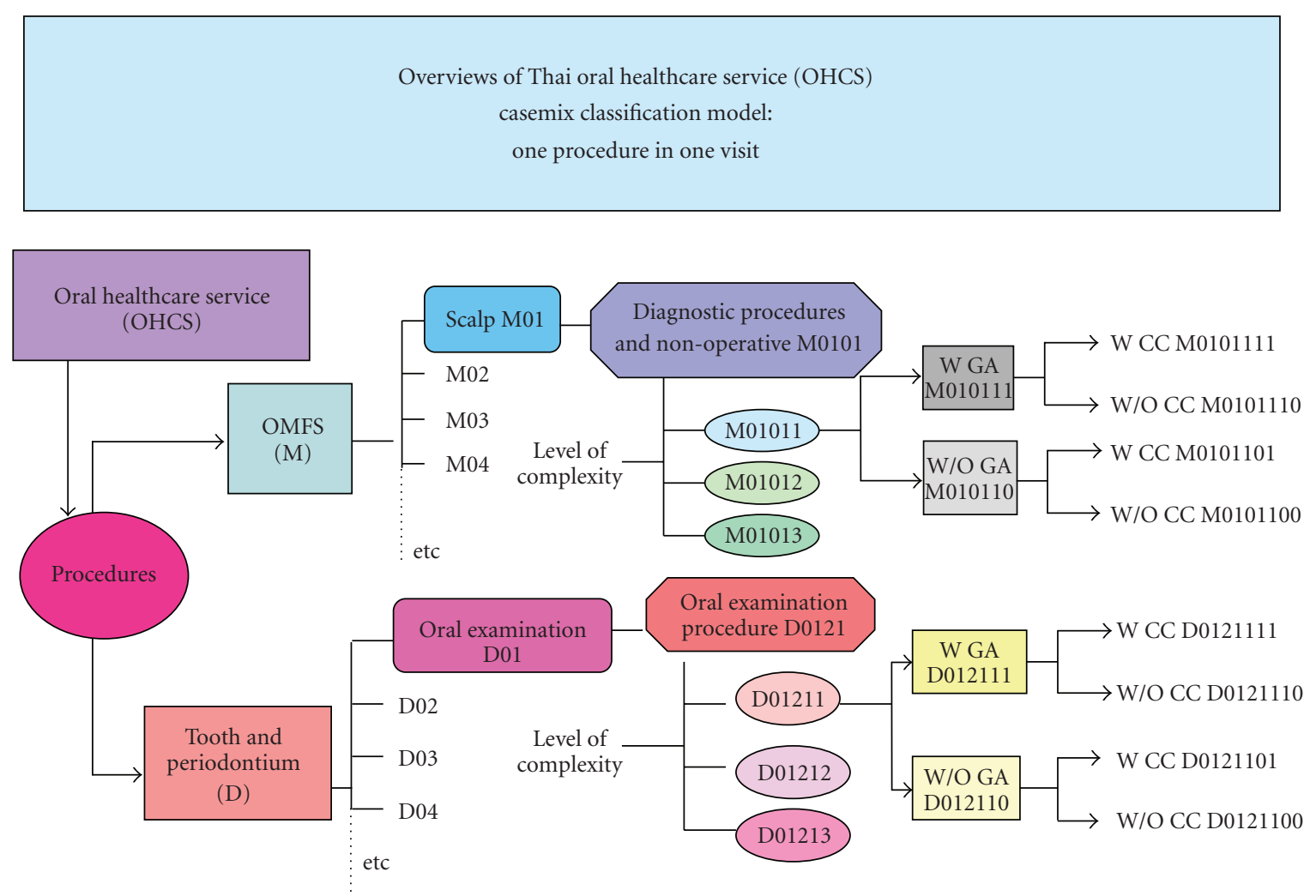

FIgURE 3: Diagram demonstrates the overviews of the Thai oral healthcare service (OHCS) casemix classification model of one procedure in one visit. $\mathrm{M}=$ oral and maxillofacial surgery (OMFS), $\mathrm{W}=$ with, $\mathrm{W} / \mathrm{O}=$ without, $\mathrm{GA}=$ general anesthesia, $\mathrm{CC}=$ complication and comorbidity.

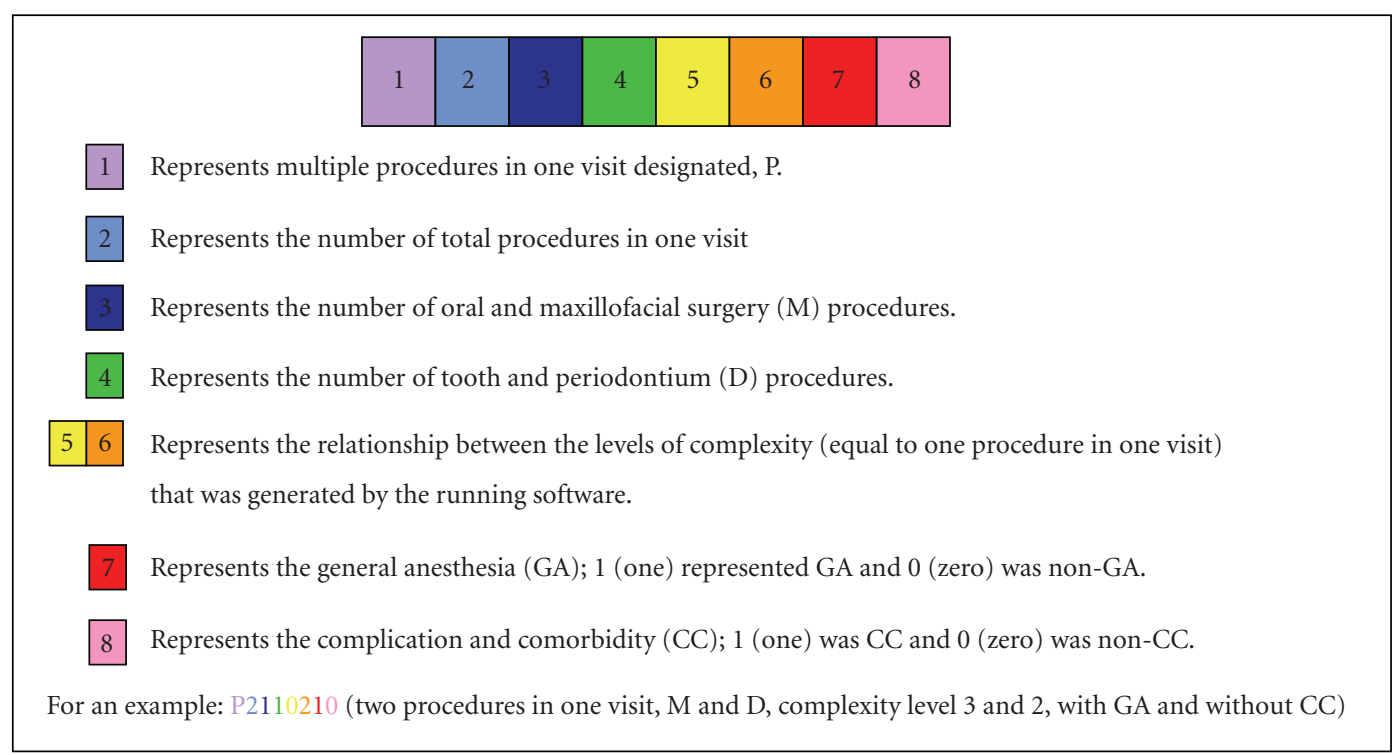

FIGURE 4: Diagram presents the casemix classification model of OHCS (multiple procedures in one visit) as represented in eight-digit codes.

clinical information and health insurance showed that the majority of the patients were female $(8,723$ cases; $54.0 \%)$, non-GA $(13,911$ cases; $86.05 \%)$, non-CC (15,708 cases; 97.17\%), and CSMBS (6,368 cases; $39.4 \%)$.
3.2. Classification. The new OHCS casemix classification model (Grouper) consisted of two major procedure categories, $M$ and D, 62 procedure clusters (Table 1), 165 subgroups of procedure clusters (Table 2), and 1,624 OHCS 
Overviews of Thai oral healthcare service (OHCS)

casemix classification model:

multiple procedures in one visit $(\mathrm{P})$

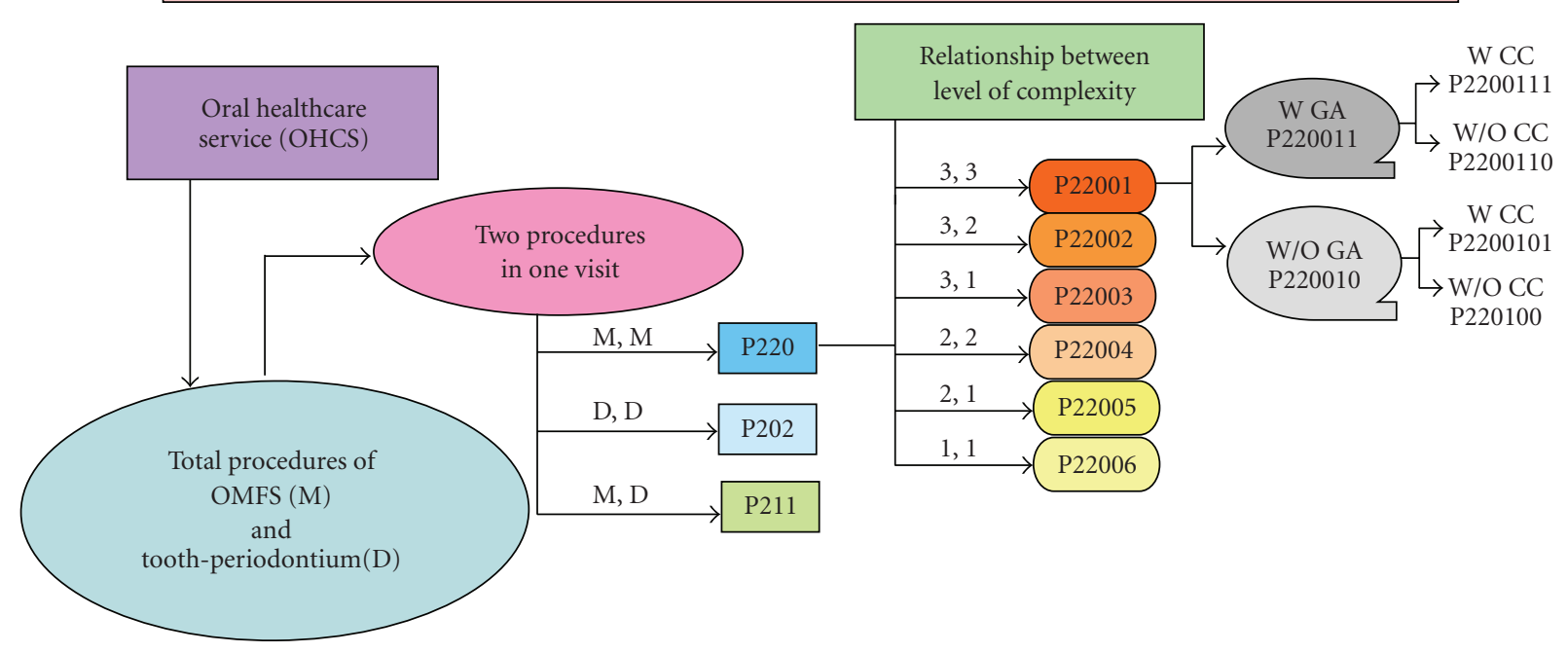

FIgURE 5: Diagram demonstrates overviews of the Thai oral healthcare service (OHCS) casemix classification model of multiple procedures in one visit $(\mathrm{P}) . \mathrm{M}=$ oral and maxillofacial surgery $(\mathrm{OMFS}), \mathrm{W}=$ with, $\mathrm{W} / \mathrm{O}=$ without, $\mathrm{GA}=$ general anesthesia, $\mathrm{CC}=\mathrm{complication}$ and comorbidity.

classifications according to the treatment procedures (Annex Table 5). Each OHCS classification described a cluster of patients with related diagnoses, requiring a similar examination and incurring similar treatment costs. There were 16,165 patients who were grouped into OHCS classifications by the grouper software. After the grouping process, only 307 OHCS classifications were achieved to cover these procedure codes. This result was likely limited by the OHCS data, as the amount available in this pilot study was not sufficient to support the OHCS grouper.

3.3. Costs. For predicting costs, regression analysis was employed. Table 3 presents the determination of the cost of $\mathrm{P}, \mathrm{D}$, and $\mathrm{M}$. Because cost did not present a normal distribution, a normal logarithmic transformation was undertaken. The predicted cost of $\mathrm{P}, \mathrm{D}$, and $\mathrm{M}$ had $\mathrm{R}^{2}$ values of 0.892 , 0.132 , and 0.122 , respectively, and the probability of the Ftest statistic was 0.000 . The results showed that the GA, CC, number of procedures in one visit, Proc (divided by the level of complexity), and LOS were associated with the costs of $\mathrm{P}$, $\mathrm{D}$, and $\mathrm{M}$.

3.4. Calibration. To ensure that the OHCS classifications reflected resource homogeneity within groups and heterogeneity between groups, the CV and RIV, respectively, were used for analysis.

The lowest CVs relative to the outpatient groups for $\mathrm{P}$, $\mathrm{D}$, and $\mathrm{M}$ were 0.02 (P2110200), 0.01 (D0843200), and 0.19 (M4004100), respectively, while the highest CVs relative to these groups for $\mathrm{P}, \mathrm{D}$, and $\mathrm{M}$ were 0.87 (P2020500), 0.99 (D0736200), and 0.83 (M4310101), respectively. The lowest CVs relative to the inpatient groups for $\mathrm{P}, \mathrm{D}$, and $\mathrm{M}$ were 0.31
(P2200511), 0 (the number of cases was less than five), and 0.22 (M4004100), respectively, while the inpatients' highest CVs for P, D, and M were 0.98 (P2200410), 0 (the number of cases was less than five), and 0.99 (M3002110), respectively. Moreover, all OHCS classifications had a CV on cost of less than one (Table 4, Annex Table 5).

The RIVs relative to the outpatient groups for P, D, and $M$ were 27,87 , and $65 \%$, respectively, while the inpatient groups' RIVs for P, D, and $\mathrm{M}$ were 16, 0 (number of cases less than five) and $22 \%$, respectively. The results showed that $100 \%$ of the OHCS classifications had a higher RIV (RIV greater than 0 ) on cost (Table 4). Both the CV and RIV analysis demonstrated the superior performance of the grouper software.

The lowest RWs in the outpatient groups for P, D, and $\mathrm{M}$ were 0.51 (P3121800), 0.14 (D0222100), and 0.30 (M1999101), respectively, while the highest RWs of the outpatient groups were 3.59 (P3121000), 21.33 (D0843200), and 7.88 (M3002200), respectively. The lowest RWs relative to the inpatient groups for $\mathrm{P}, \mathrm{D}$, and $\mathrm{M}$ were 0.13 (P2200600), 0 (the number of cases was less than five) and 0.02 (M1999100), respectively, while the inpatients' highest RWs were 2.03 (P3300510), 0 (the number of cases was less than five), and 3.46 (M3202210), respectively (Table 4, Annex Table 5). A high RW indicated a higher case complexity and more resources required for treatment than for low RW cases. Moreover, RW was the most important result of the calibration because it was the determinant for the payment to healthcare providers.

3.5. Payment. This study calculated the base rate characteristics by splitting cases into three main treatment groups 
TABLE 3: Multiple regressions of the cost of multiple procedures (P), the cost of OMFS (M), and the cost of tooth and periodontium (D).

\begin{tabular}{|c|c|c|c|c|c|c|c|c|c|c|}
\hline & & \multicolumn{3}{|c|}{ Cost of multiple procedures $(\mathrm{P})$} & \multicolumn{3}{|c|}{ Cost of OMFS (M) } & \multicolumn{3}{|c|}{ Cost of tooth and periodontium (D) } \\
\hline & & \multicolumn{3}{|c|}{$95 \% \mathrm{CI}$} & \multicolumn{3}{|c|}{$95 \% \mathrm{CI}$} & \multicolumn{3}{|c|}{$95 \% \mathrm{CI}$} \\
\hline & & Odds-ratio & Lower-upper & $P$-value & $\begin{array}{c}\text { Odds- } \\
\text { ratio }\end{array}$ & Lower-upper & $P$-value & $\begin{array}{l}\text { Odds- } \\
\text { ratio }\end{array}$ & Lower-upper & $P$-value \\
\hline \multirow[t]{2}{*}{ Gender } & $\begin{array}{l}\text { Male } \\
\text { (reference) }\end{array}$ & & & & & & & & & \\
\hline & Female & 0.97 & $0.89-1.13$ & .973 & 1.14 & $1.02-1.19$ & .009 & 0.95 & $0.88-1.03$ & .243 \\
\hline \multirow[t]{4}{*}{ Age } & $\begin{array}{l}0-22 \\
\text { (reference) }\end{array}$ & & & & & & & & & \\
\hline & $23-40$ & 1.04 & $0.89-1.22$ & .671 & 1.56 & $1.39-1.74$ & $<.001$ & 1.02 & $0.91-1.15$ & .633 \\
\hline & $41-54$ & 0.88 & $0.75-1.03$ & .121 & 1.17 & $1.05-1.31$ & .04 & 0.82 & $0.73-0.92$ & .001 \\
\hline & $54+$ & 0.85 & $0.73-0.99$ & .039 & 1.17 & $1.15-1.30$ & .03 & 0.79 & $0.71-0.88$ & $<.001$ \\
\hline \multirow[t]{2}{*}{ GA } & $\begin{array}{l}\text { Non-GA } \\
\text { (reference) }\end{array}$ & & & & & & & & & \\
\hline & GA & 295.78 & $162.41-538.67$ & $<.001$ & 1.57 & $1.49-1.66$ & $<.001$ & 2386.74 & 891.84-6387.39 & $<.001$ \\
\hline \multirow[t]{4}{*}{$\begin{array}{l}\text { Number of } \\
\text { procedures }\end{array}$} & $\begin{array}{l}1 \\
\text { (reference) }\end{array}$ & & & & & & & & & \\
\hline & 2 & 9.55 & $8.72-12.45$ & .033 & 1.02 & $1.01-1.03$ & $<.001$ & 1.02 & $1.01-1.02$ & $<.001$ \\
\hline & 3 & 2.72 & $1.35-4.56$ & $<.001$ & 1.21 & $1.16-1.28$ & $<.001$ & 1.19 & $1.14-1.23$ & $<.001$ \\
\hline & 4 & 8.68 & $6.78-11.34$ & $<.001$ & 1.16 & $1.12-1.20$ & $<.001$ & 1.16 & $1.13-1.27$ & $<.001$ \\
\hline \multirow[t]{2}{*}{ CC } & $\begin{array}{l}\text { Non-CC } \\
\text { (reference) }\end{array}$ & & & & & & & & & \\
\hline & $\mathrm{CC}$ & 3.25 & $2.31-4.57$ & $<.001$ & 1.17 & $1.10-1.31$ & $<.001$ & 15.76 & $11.25-21.96$ & $<.001$ \\
\hline \multirow[t]{2}{*}{ Complexity } & $\begin{array}{l}1 \\
\text { (reference) }\end{array}$ & & & & & & & & & \\
\hline & $2-3$ & 3.81 & $2.31-4.57$ & $<.001$ & 1.91 & $1.89-1.92$ & $<.001$ & 1.91 & $1.89-1.92$ & $<.001$ \\
\hline \multirow[t]{2}{*}{ LOS } & $\begin{array}{l}\text { LE21 } \\
\text { (reference) }\end{array}$ & & & & & & & & & \\
\hline & GE22 & 0.15 & $0.06-0.33$ & $<.001$ & 1.53 & $1.38-1.73$ & $<.001$ & 0.02 & $0.05-0.08$ & $<.001$ \\
\hline
\end{tabular}

Adjusted cost of multiple procedures (P) $R^{2}=0.892$, cost of OMFS (M) $R^{2}=0.122$, and cost of tooth and periodontium (D) $R^{2}=0.132$

$\mathrm{GA}=$ general anesthesia, Number of procedures = total procedures in one visit, $\mathrm{CC}=$ complication and comorbidity

Complexity $=$ level of complexity $(1=$ simple procedure, $2=$ complex procedure, $3=$ multidisciplinary or complicated procedure $)$

LOS $=$ length of stay (LE21 = less than and equal to 21, GE22 = more than 21$)$.

TABLE 4: Summary of the statistical analysis of the coefficient of variation (CV), reduction in variance (RIV), and relative weight (RW).

\begin{tabular}{lcccccccc}
\hline \multirow{2}{*}{ OHCS } & \multicolumn{2}{c}{$N$ (cases) } & \multicolumn{2}{c}{ CV } & \multicolumn{2}{c}{ RIV } & \multicolumn{2}{c}{ RW } \\
& Inpatient & Outpatient & Inpatient & Outpatient & Inpatient & Outpatient & Inpatient & Outpatient \\
\hline $\mathrm{P}$ & 365 & 7,832 & $0.31-0.98$ & $0.02-0.87$ & $16 \%$ & $27 \%$ & $0.13-2.03$ & $0.51-3.59$ \\
$\mathrm{D}$ & 3 & 2,619 & N/A & $0.01-0.99$ & N/A & $87 \%$ & N/A & $0.14-21.33$ \\
$\mathrm{M}$ & 2,341 & 3,005 & $0.22-0.99$ & $0.19-0.83$ & $22 \%$ & $65 \%$ & $0.02-3.46$ & $0.30-7.88$ \\
\hline
\end{tabular}

$\mathrm{P}=$ multiple procedures in one visit, $\mathrm{D}=$ tooth and periodontium, $\mathrm{M}=$ oral and maxillofacial surgery (OMFS)

$\mathrm{CV}=$ coefficient of variation, $\mathrm{RIV}=$ reduction in variance, $\mathrm{RW}=$ relative weight, $\mathrm{N} / \mathrm{A}=$ not applicable.

consisting of $\mathrm{P}, \mathrm{D}$, and $\mathrm{M}$ and two patient groups consisting of inpatient and outpatient. The results showed that the highest base rate among the three main treatment groups relative to the outpatient groups and the inpatient groups were $\mathrm{D}$ and $\mathrm{P}$, respectively.

\section{Discussion}

This is a study of the preliminary development of a new casemix classification system related to ICD-10-TM in Thai OHCS. The results indicated that the new casemix system 


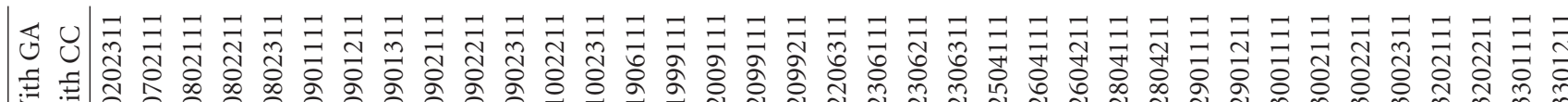

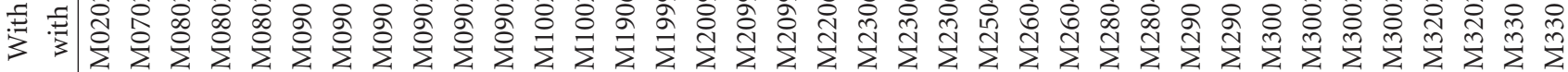

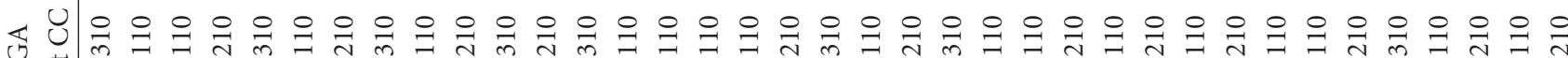

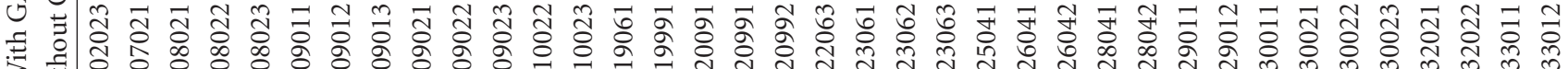

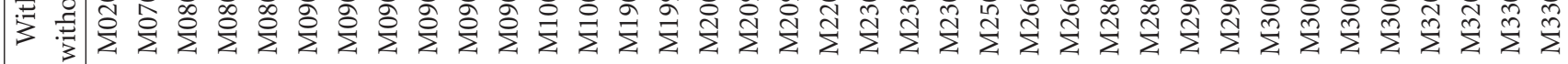

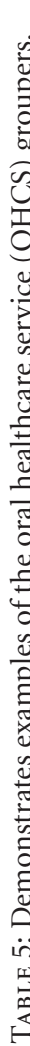

萑

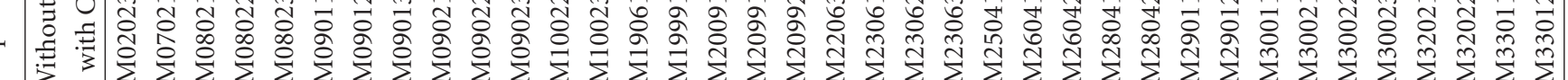

苻

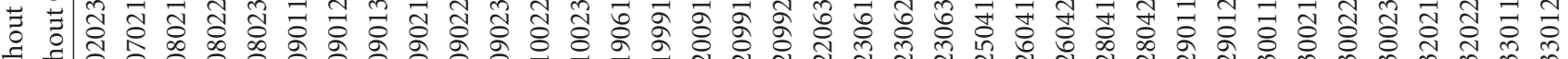

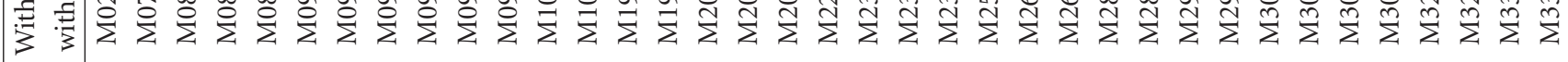
4

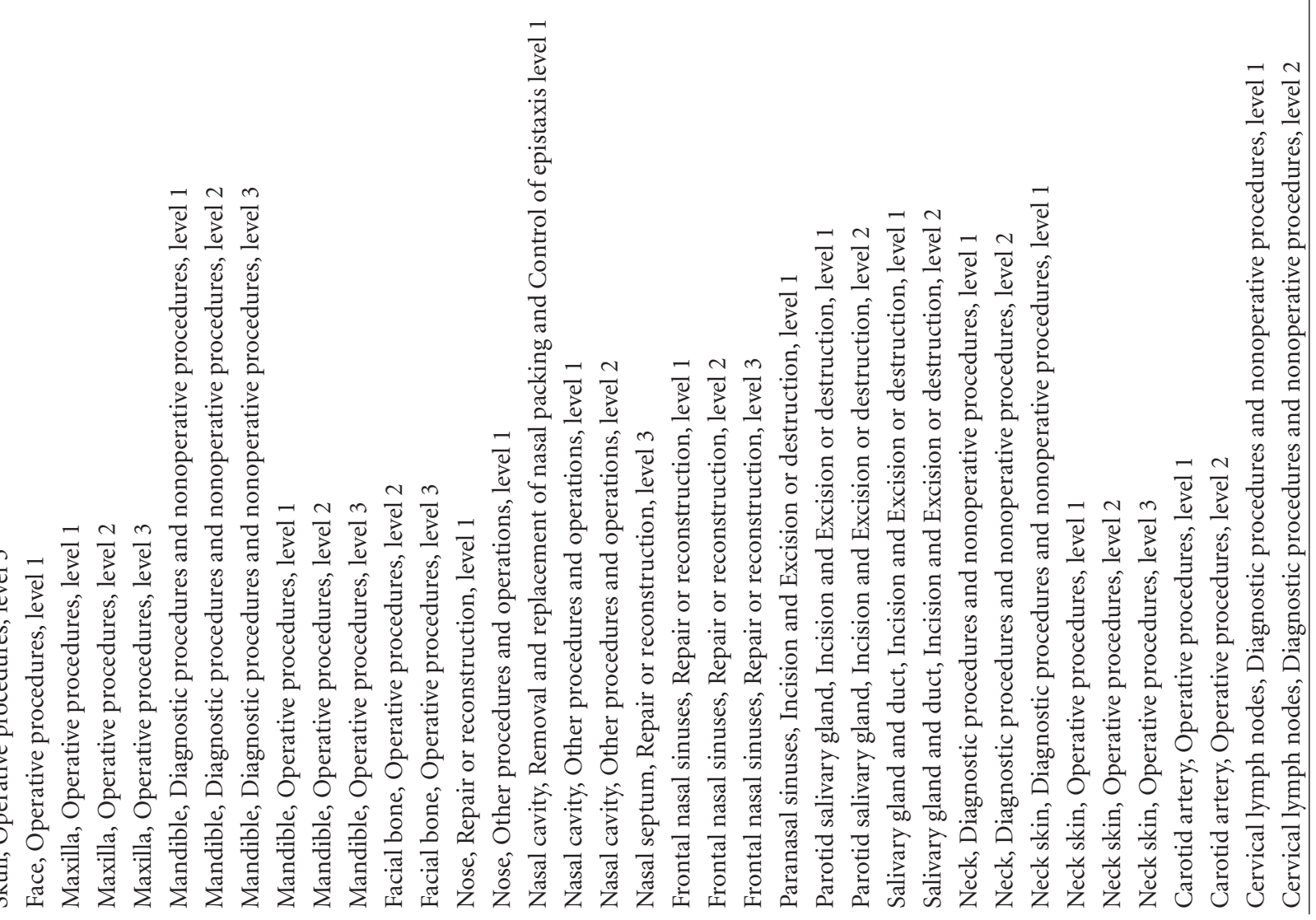




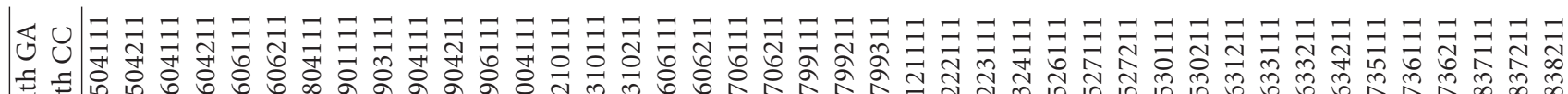

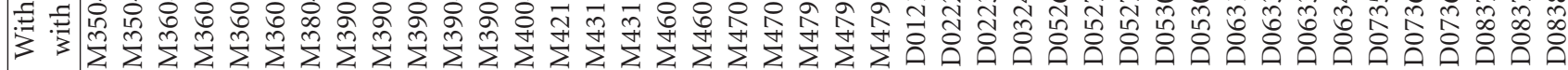

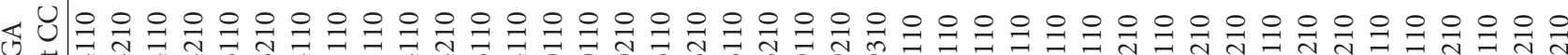

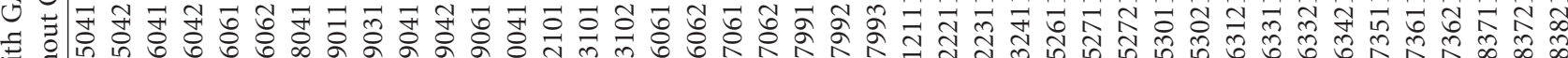

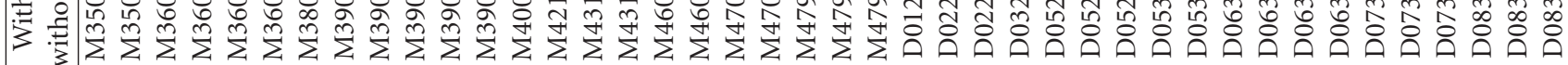

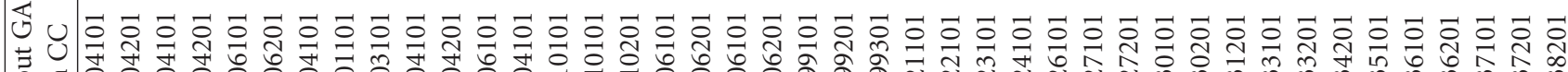

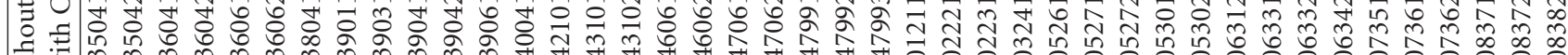

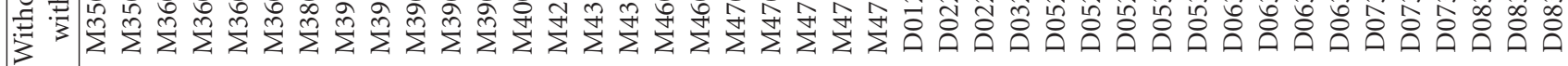

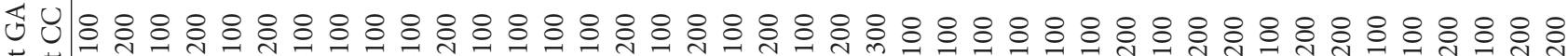

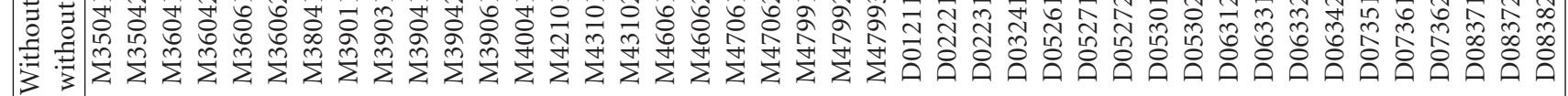

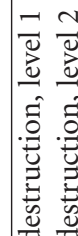
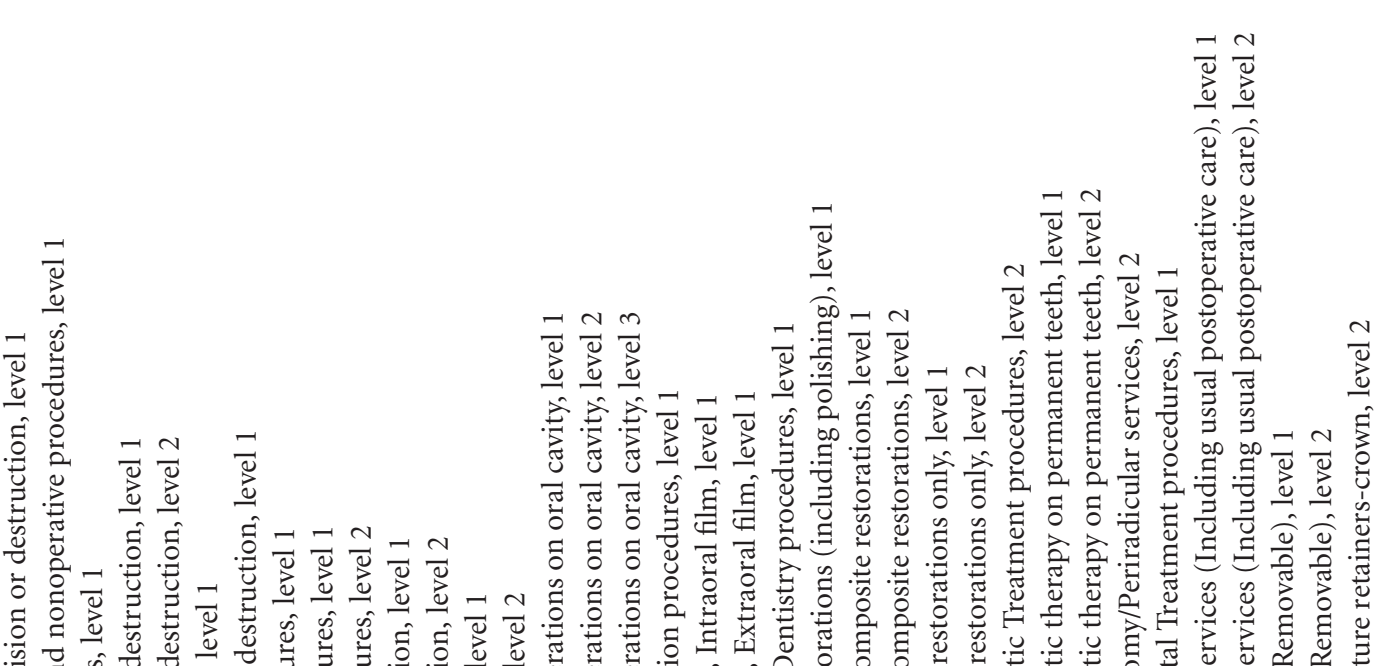

t)

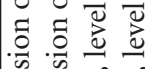

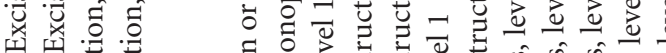

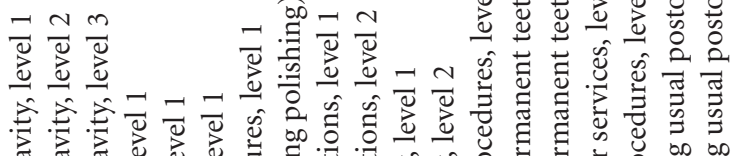

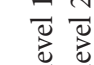

.$\check{.}$

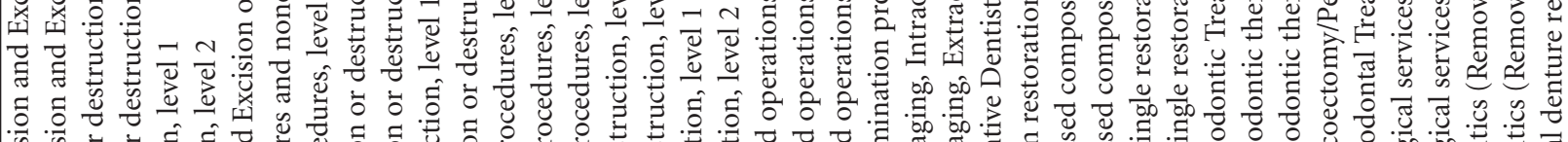
है द्वु

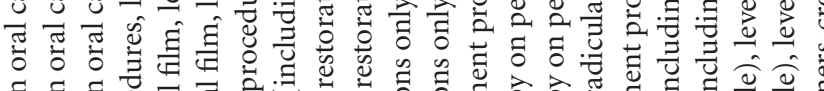

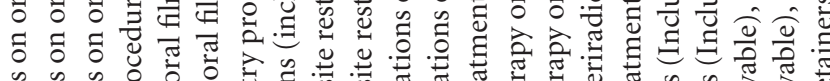

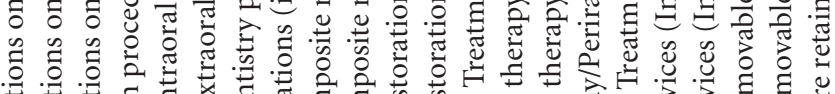

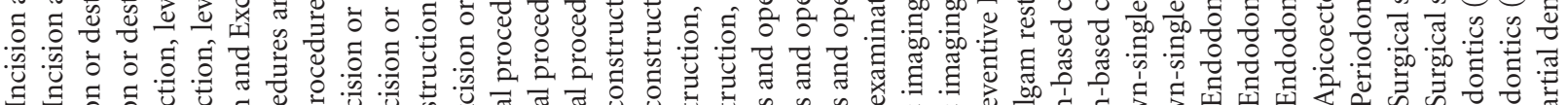
$\exists \Xi$.

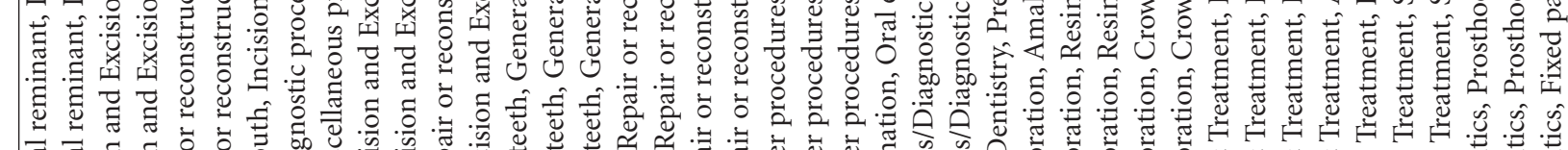

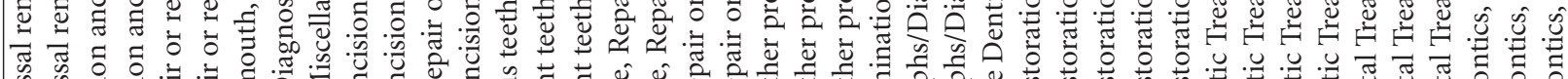

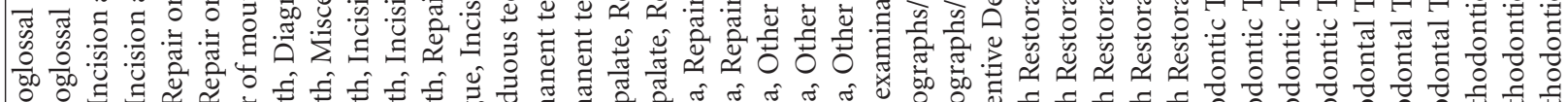

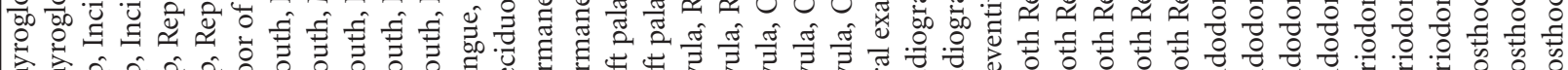

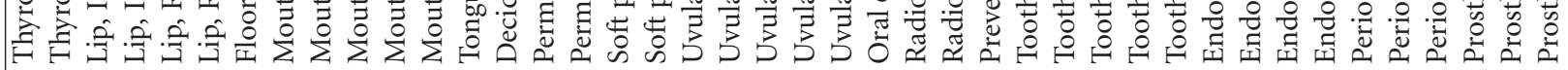




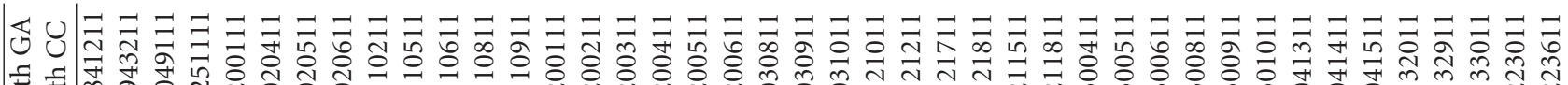

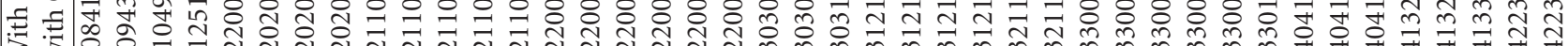

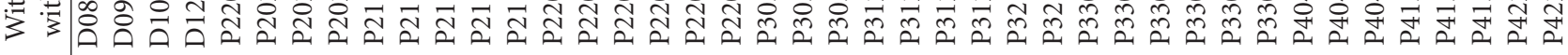

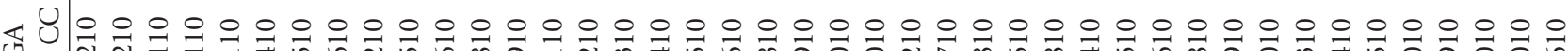

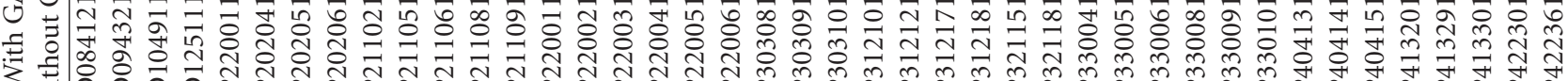
उ

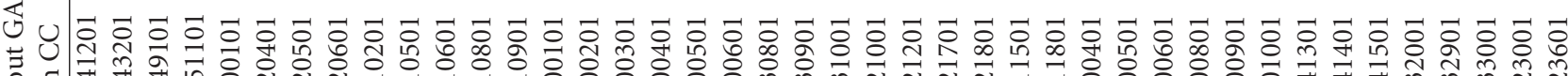
F च F

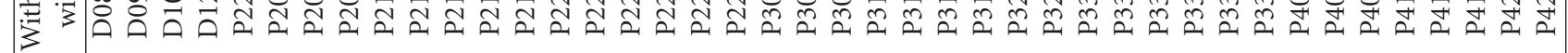

\section{芯}

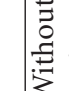

苛

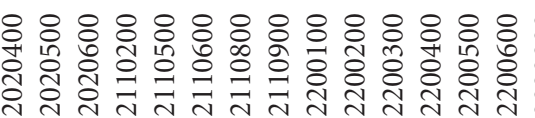
$\circ$
$\&$

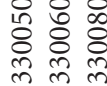

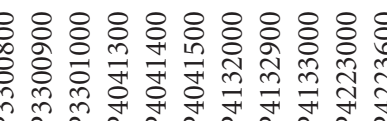

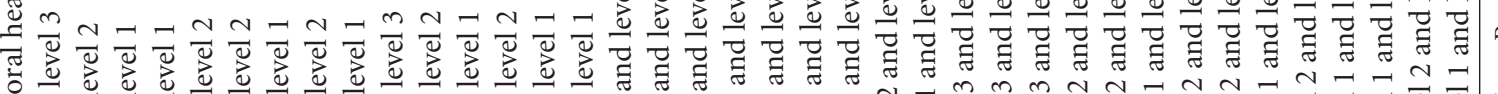

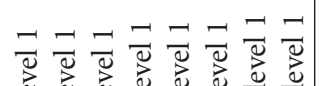

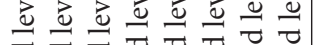

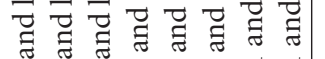

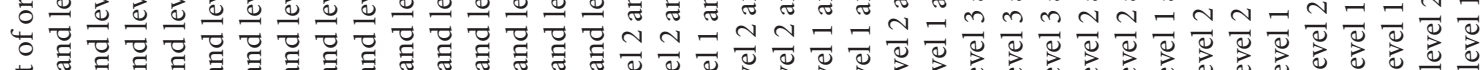

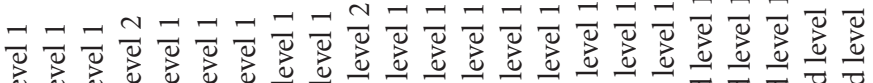

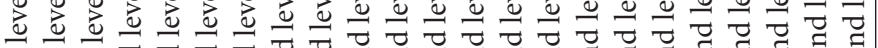

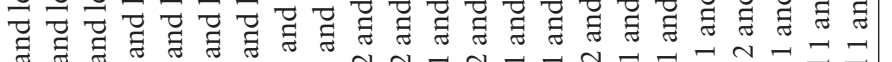

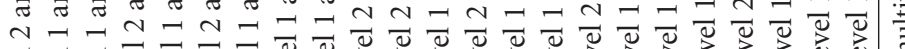

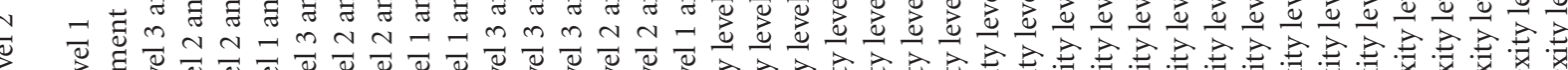

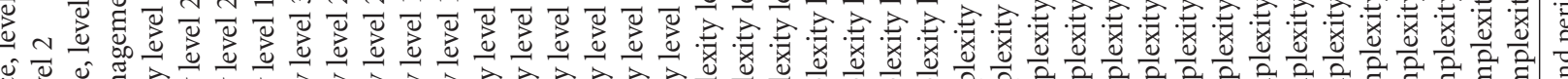

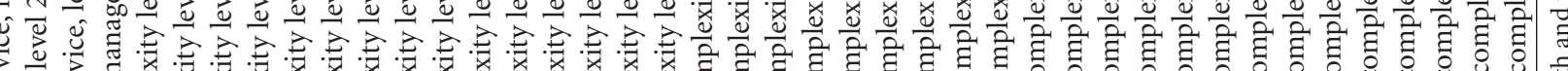
क

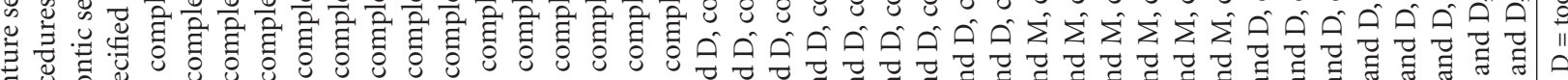

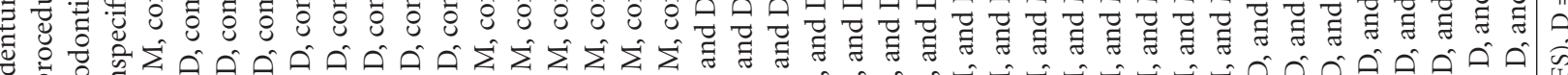
चु

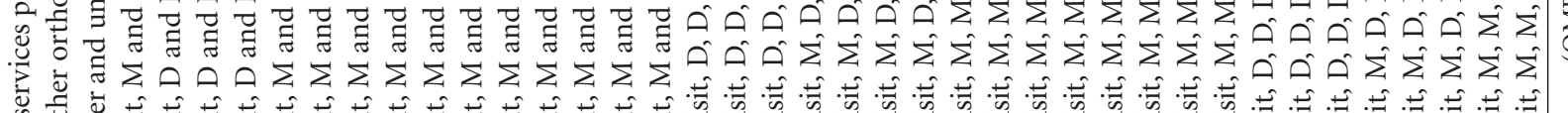

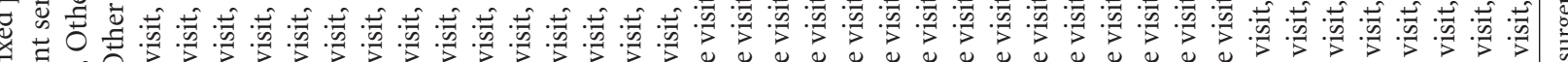

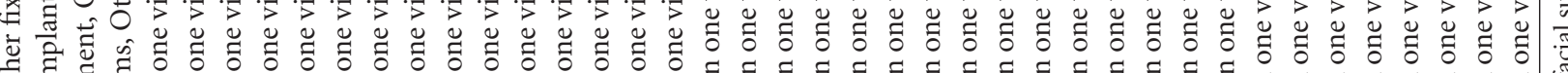

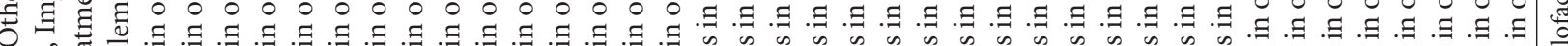

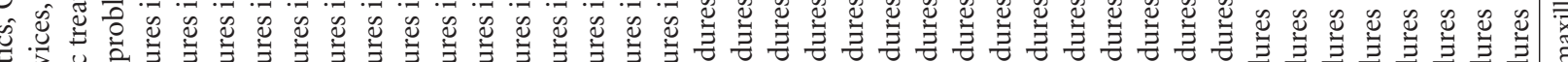

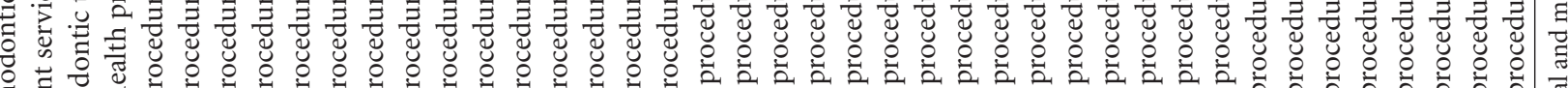

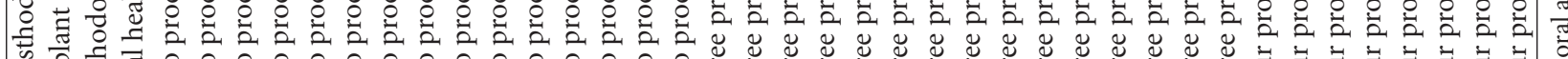

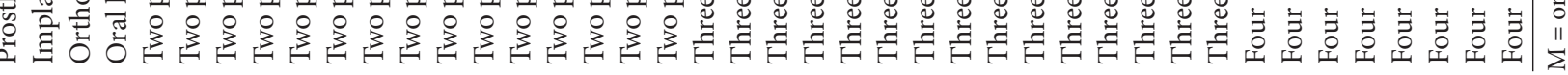


was reliable and could possibly be utilized as a first version. However, many points need to be discussed.

4.1. Coding. In Thailand, the healthcare system has implemented ICD-10 for Dx and ICD-9-CM for Proc for many years. Recently, ICD-10-TM has been implemented to provide more details in the OHCS coding by modifying it with International Classification of Disease to Dentistry and Stomatology (ICD-DA) for Dx and CDT for Proc. The most recent modification of the codes was finished in 2003 [23, $24]$. Thus, the ICD-10-TM provides an advantage in terms of accuracy and comprehensive coverage for Dx and Proc. It is unique, but similar to the CDT and matched with Proc one by one while ICD-9-CM has many Proc for each code. These differences indicate that ICD-10-TM was suitable, although challenging, for this study.

4.2. Classification. The development of the new casemix classification for OHCS concentrated on practical application of the IR-DRG that was instituted by $3 \mathrm{M}$ Health Information System. IR-DRG was able to classify inpatient and outpatient status and was also useful for appraising the potential for replacement on both short stay and ambulatory treatments [31]. Taking this fact into consideration, the new casemix classification was classified by the nature of the patients' procedures rather than by their diagnoses. This classification system was developed to allow the translation of dental procedures into eight-digit codes using various variables to obtain a homogenous resource group.

4.3. Costs. There are a variety of methods for estimating the provider's cost. However, each method has limitations. The cost of OHCS varies depending upon several factors: the characteristics of the OHCS, the scope and complexity of the treatment, the specialty and experience of physician, the high investment cost, and the location of the practice. It was difficult to measure the total submitted charges for cases in each OHCS classification. Therefore, the cost in this study was calculated based on the use of the patient payment to estimate the provider's cost.

It was expected that this method would be suitable to calibrate the OHCS classification in this study. However, a future study using a resource-based relative value scale (RBRVS) would be recommended. Because RBRVS is a schema that is used to calculate what medical providers should be paid, it assigns a relative value unit (RVUs) to each physician service that is based on three items: the physician, the practice expense, and the malpractice expense. This schema is currently used by Medicare in the United States and by nearly all Health Maintenance Organizations (HMOs) [32-34]. In 2009, Relative Value Studies Incorporated (RVSI) of Denver, Colorado developed Relative Values for Dentists (RVD), a RBRVS for dentistry that is currently indexed to the Current Dental Terminology (CDT) and supplemented by additional coding as recommended by practicing dentists [35].
4.4. Calibration and Payment. Because of the wide range of costs among the set of $\mathrm{P}, \mathrm{D}, \mathrm{M}$, inpatient, and outpatient categories, the weight should reflect the relative cost of providing care and the health resources required in each DRG. A CV of less than one and a higher RIV would be expected in the new OHCS classification. Thus, the RIV, RW, and base rate characteristics were split into three main treatment groups consisting of $\mathrm{P}, \mathrm{D}$, and $\mathrm{M}$ and two patient groups consisting of inpatient and outpatient for the following reasons.

(i) The higher RIV reflects the better performance of the grouping. However, P had the lowest RIV in both inpatient and outpatient groups because P included multiple procedures in one visit, and in some cases $\mathrm{P}$ had $\mathrm{M}$ and $\mathrm{D}$ in one visit. $\mathrm{P}$ also had more data and variation than did the other groups. The RIV of $\mathrm{M}$ of the inpatient group was lower than the RIV of $\mathrm{M}$ of the outpatient group because all inpatient procedures were major surgeries with GA, complex, and costly procedures. D had the highest RIV in the outpatient group because all procedures in the outpatient group were minor surgeries, tooth and periodontium treatment, without GA.

(ii) The procedures of each group were different according to the anatomy group, root operation, and total procedures in one visit.

(iii) Elementary procedures in the OHCS were wildly different in each group. The OHCS was mostly focused on handiwork. OHCS was intensively skilled, time-consuming labor with a high investment cost for the equipment, instruments, and materials [36].

Taken together, this new OHCS grouper has been potentially implemented in Thailand. However, in some countries that use ICD-10 for Dx, ICD-9-CM for Proc and DRG for budget allocation, this information of the mapping process could be used as a guideline to further develop their own systems. Moreover, the benefits of the DRG grouper for OHCS could be used for expenditure estimation, resource allocation, payment, and oral healthcare finance focus.

4.5. Limitation. The problems related to the implementation of a new casemix classification for OHCS are elaborated as follows.

(i) Although computerized information systems are widely used in Thailand, only a few hospitals provided good clinical data that were ready to use [11]. This was an important issue for OHCS information because ICD-10 and ICD-9-CM were not commonly used for recording with the same standardization. This problem was likely due to the limited data from OHCS in Thailand, which could not support an OHCS grouper. 
(ii) The diagnoses and procedures of the OHCS coding system are scattered throughout the ICD-10 and ICD-9-CM, making them difficult to find and use. Moreover, currently OHCS codings are not being used effectively in dentistry.

(iii) The OHCS patient data from this study did not involve patients from university hospitals because the patients in university hospitals had more heterogeneity in their diagnoses and services than did other hospitals. In addition, OHCS classification subgroups may be needed to more precisely describe the resource consumption in the university hospital setting.

(iv) There were 1,624 OHCS classifications. In this pilot study, the data were limited and were not sufficient to support the OHCS grouper. A large number of OHCS classifications might be difficult to handle as a good payment tool. In the future, the OHCS classification should decrease the number of groups to provide more efficiency and effectiveness in payment.

(v) OHCS cost weights were calculated using only cost data from some areas that might not be applicable to all hospitals in Thailand. This indicated that an expanded number of cases and data from additional hospitals would give a more exact cost weight.

\section{Conclusion}

This study demonstrated the validity of the new OHCS classification, showing high homogeneity of the cases within each group and heterogeneity of the cases between each group. Furthermore, it could be used to predict and control production costs. Therefore, this OHCS casemix classification has the potential to be used in global decisionmaking in the future. Moreover, some countries using ICD10 for diagnoses, ICD-9-CM for procedures, and DRG grouper for budget allocation might be able to apply this mapping process as a guideline to develop their own system, which might benefit from the use of the DRG grouper for expenditure estimation, resource allocation, payment, and healthcare finance focus.

\section{Acknowledgments}

The authors would like to thank Monbukagakusho scholarship and Chulalongkorn University Centenary Academic Development Project for support this research. They also thank the staffs of Chonburi, Phrapokklao Chantaburi, and Queen Sirikit hospitals that provided helpful data handling, Assistant Professor Yosananda Chantravekin and Dr. Kanjana Singkharotai for reviewing the ICD-10-TM codes related to OHCS, and Mr. Monthon Buakaew from MOPH for grouping. Finally, thanks are due to an anonymous person for helpful comments on the paper.

\section{References}

[1] J. R. Antos, "Health care financing in Thailand: modeling and sustainability. Mission report to the World Bank," August 2007, http://siteresources.worldbank.org/INTTHAILAND/Resources/333200-1182421904101/2007aug-health-financingmodeling.pdf.

[2] D. Hughes and S. Leethongdee, "Universal coverage in the land of smiles: lessons from Thailand's 30 Baht health reforms," Health Affairs, vol. 26, no. 4, pp. 999-1008, 2007.

[3] S. Pannarunothai, "Equity in health: concept and data in Thailand," Journal of the Medical Association of Thailand, vol. 86, no. 9, pp. 889-895, 2003.

[4] B. Phuaphanprasert, The Alternative Resource Allocation Using Thai Psychiatric Casemix Approach, Health Systems Research Institute, Nonthaburi, Thailand, 2006.

[5] S. Pannarunothai, Health Economics in the Health Reform Era, Surasi Graphics, Phitsanulok, Thailand, 2nd edition, 2001.

[6] P. Lapying and W. Tieankingkeawiv, "Public oral care provision under the Universal Health Care Coverage Project," Journal of Health Science, vol. 13, pp. 67-81, 2004.

[7] P. Lapying and B. Jittrungreung, "Public oral care cost in fiscal year 2003," Journal of Health Science, vol. 13, pp. 56-66, 2004.

[8] P. Lapying, A. Detpithak, M. Torsavetpong, K. Lakorn, and C. Tangvijitsakul, "Oral health system after the 5th year implementation of the Universal Coverage Health System: a case study in 4 provinces," Research Report, Dental Health Bureau, Department of Health, Ministry of Public Health, Nonthaburi, Thailand, 2009.

[9] P. Lapying, "Public — private mixed model for oral health care under the Universal Health Coverage Project: a case study of Bangkok," Journal of Health Science, vol. 13, no. 6, pp. 935951, 2004.

[10] K. Tisayaticom, W. Patcharanarumol, and V. Tangcharoensathien, "Unit cost analysis: standard and quick methods," Journal of Health Science, vol. 10, pp. 359-367, 2001.

[11] S. Pannarunothai, Diagnosis Related Groups (DRG): Development in Thailand, Health Systems Research Institute, Nonthaburi, Thailand, 2001.

[12] F. H. R. France, "Case mix use in 25 countries: a migration success but international comparisons failure," International Journal of Medical Informatics, vol. 70, no. 2-3, pp. 215-219, 2003.

[13] C. Suwanmala, S. Chadraprasert, and N. Noppakun, Costing the Diagnostic Related Group of disease (DRGs) a case study of Chulalongkorn hospital, Dissertation, College of Public Health, Chulalongkorn University, 1994.

[14] H. Mikkola, I. Keskimäki, and U. Häkkinen, "DRG-related prices applied in a public health care system-can Finland learn from Norway and Sweden?" Health Policy, vol. 59, no. 1, pp. 37-51, 2002.

[15] A. J. Senagore, A. Brannigan, R. P. Kiran, K. Brady, and C. P. Delaney, "Diagnosis-related group assignment in laparoscopic and open colectomy: financial implications for payer and provider," Diseases of the Colon and Rectum, vol. 48, no. 5, pp. 1016-1020, 2005.

[16] K. Kawabuchi, "Payment systems and considerations of case mix — are diagnosis-related groups applicable in Japan?" PharmacoEconomics, vol. 18, no. 1, pp. 95-110, 2000.

[17] N. Upakdee, S. Pannarunothai, T. Sakunphanit, and R. Preechachard, "Casemix adjustment for outpatient service: a tool for resource allocation of social security population in Thailand," BMC Health Services Research, vol. 7, 2007. 
[18] S. Kongsawatt and S. Pannarunothai, "Cost per DRG relative weight for regional and community hospitals," Journal of Health Science, vol. 10, pp. 391-399, 2001.

[19] S. Pannarunothai, D. Patmasiriwat, and S. Srithamrongsawat, "Universal health coverage in Thailand: ideas for reform and policy struggling," Health Policy, vol. 68, no. 1, pp. 17-30, 2004.

[20] J. L. Leake, P. A. Main, and W. Sabbah, "A system of diagnostic codes for dental health care," Journal of Public Health Dentistry, vol. 59, no. 3, pp. 162-170, 1999.

[21] P. Phantumvanit, R. A. Monteil, T. F. Walsh et al., " 4.2 Clinical records and global diagnostic codes," European Journal of Dental Education, vol. 6, no. 3, pp. 138-146, 2002.

[22] American Dental Association, Current Dental Terminology 2007/2008, American Dental Association, Chicago, Ill, USA, 5th edition, 2006.

[23] Bureau of Policy and Strategy Office of the Permanent Secretary Ministry of Public Health, ICD-10-TM Tabular List of Diseases Volume 1, Bureau of Policy and Strategy Office of the Permanent Secretary Ministry of Public Health, Nonthaburi, Thailand, 2003.

[24] Bureau of Policy and Strategy Office of the Permanent Secretary Ministry of Public Health, ICD-10-TM Tabular List of Procedures Volume 3, Bureau of Policy and Strategy Office of the Permanent Secretary Ministry of Public Health, Nonthaburi, Thailand, 2004.

[25] The National Health Security Office, Thai DRG Version 4.0, The National Health Security Office, Nonthaburi, Thailand, 2007.

[26] 3M Health Information System, IR-DRG Version 1.1, 3M Health Information System, St. Paul, Minn, USA, 2001.

[27] C. M. Yang and W. Reinke, "Feasibility and validity of international classification of diseases based case mix indices," BMC Health Service Research, vol. 6, article 125, 2006.

[28] R. F. Averill, J. H. Muldoon, J. C. Vertress, et al., "The evolution of casemix measurement using Diagnosis Related Groups (DRGs)," Research Report 5-98, 3M Health Information System, 1998.

[29] Office of Evaluation and Inspections, "Medicare hospital prospective payment system: how DRG rates are calculated and updated," 2001, http://oig.hhs.gov/oei/reports/oei-09-0000200.pdf.

[30] B. Reid and S. Sutch, "Comparing diagnosis-related group systems to identify design improvements," Health Policy, vol. 87, no. 1, pp. 82-91, 2008.

[31] Canadian Institute for Health Information, "Acute care grouping methodologies: from Diagnosis Related Groups to Case Mix Groups redevelopment," 2004, http://secure.cihi.ca/ cihiweb/en/downloads/Acute_Care_Grouping_Methodologies 2004_e.pdf.

[32] E. R. Becker, D. Dunn, P. Braun, and W. C. Hsiao, "Refinement and expansion of the Harvard resource-based relative value scale: the second phase," American Journal of Public Health, vol. 80, no. 7, pp. 799-803, 1990.

[33] T. R. Cowper, "The relative value of provider work for maxillofacial prosthetic services," Journal of Prosthetic Dentistry, vol. 75, no. 3, pp. 294-301, 1996.

[34] S. Maxwell, S. Zuckerman, and R. A. Berenson, "Use of physicians' services under medicare's resource-based payments," New England Journal of Medicine, vol. 356, no. 18, pp. 1853 1861, 2007.
[35] Relative Value Study Incorporated, 2009, http://www.rvsdata.com.

[36] P. Lapying, Research Project Oral Health in Thailand: Financing for Justice, Dental Health Bureau, Department of Health, Ministry of Public Health, Nonthaburi, Thailand, 2004. 


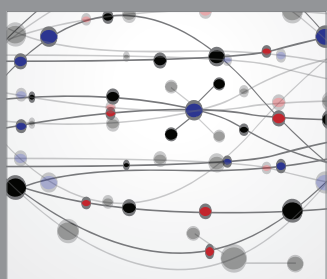

The Scientific World Journal
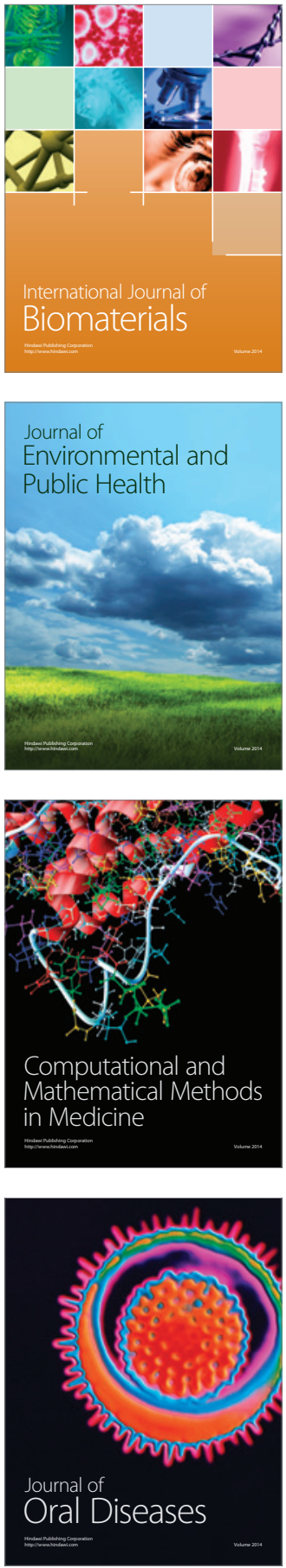
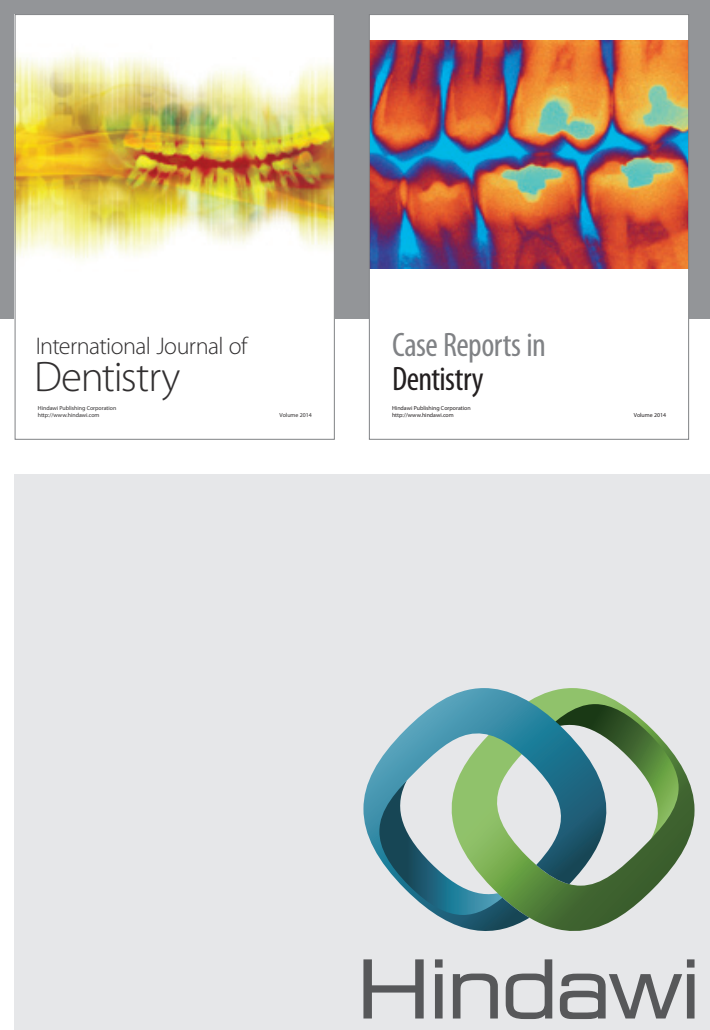

Submit your manuscripts at

http://www.hindawi.com
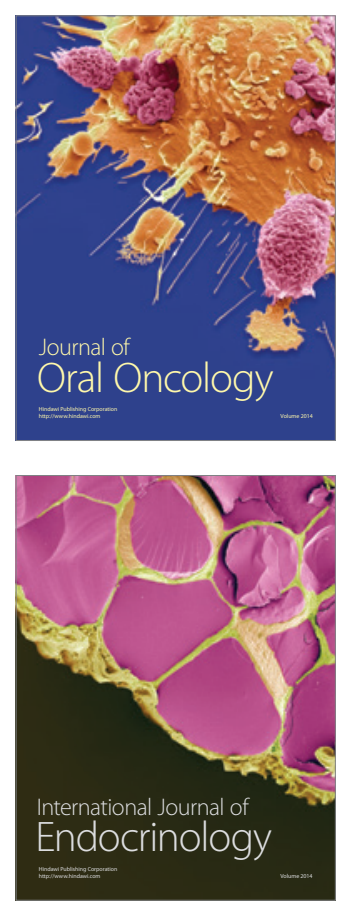
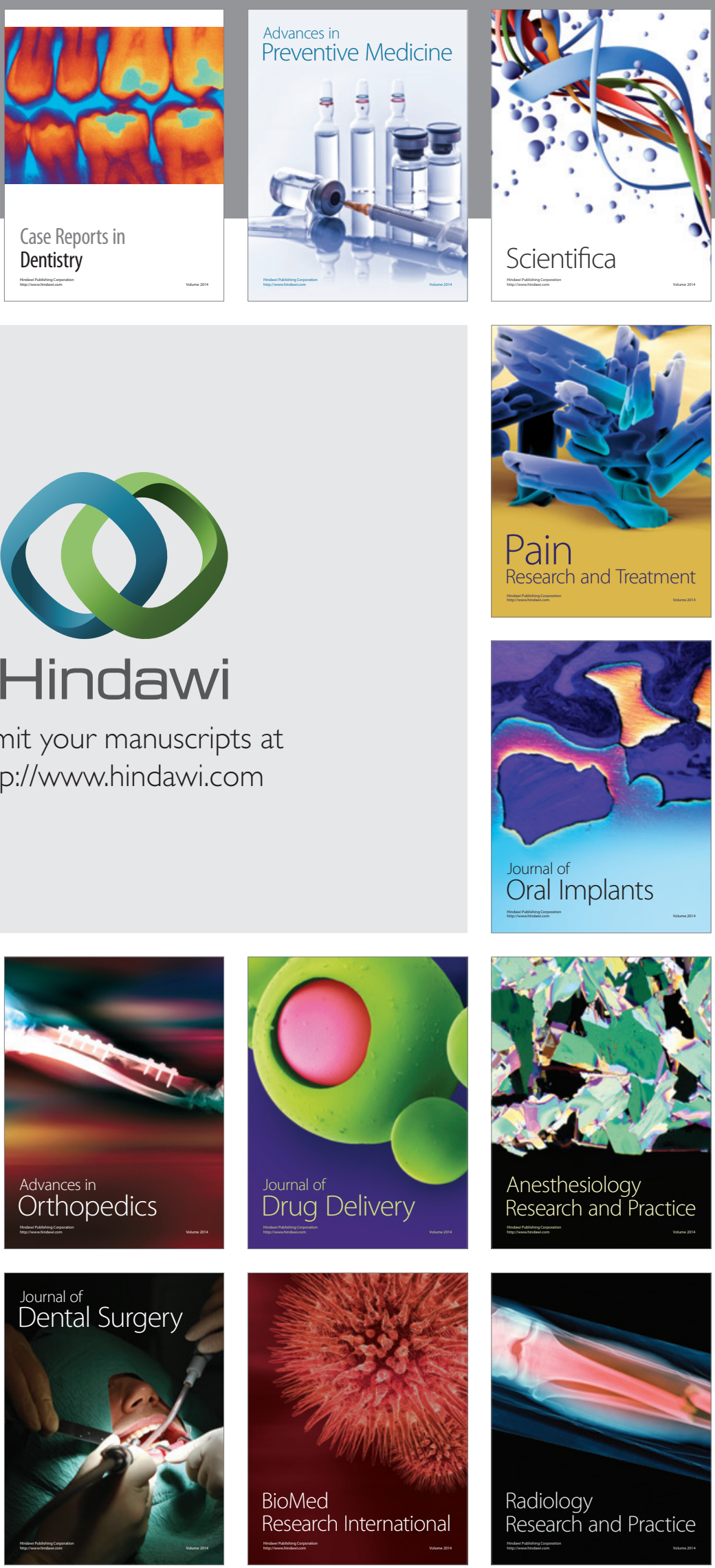